(C) Dereito Vol.27, noEXT:13-39 (Xaneiro-Decembro, 2018) • ISSN 1132-9947

\title{
TRANSPARENCIA Y DEMOCRACIA: SOBRE LAS MOTIVACIONES Y BASES EPISTEMOLÓGICAS DE LA LEY GALLEGA 1/2016
}

Transparency and democracy: about the motivations and epistemological basis of the galician law 1/2016

DOI: http://dx.doi.org/10.15304/dereito.27.Ext.5784

JosÉ JULIO FERnÁNDEZ RodRÍGUEZ

Profesor Titular de Derecho Constitucional

Universidade de Santiago de Compostela

josejul.fernandez@usc.es

\section{Resumen}

El principio de transparencia se ha convertido en un elemento nuclear de la democracia, regulado tanto en la legislación estatal como en la autonómica gallega. Para su mejor entendimiento y comprensión resulta necesario conocer las bases epistemológicas de tal principio, lo que hacemos en este trabajo en sus líneas esenciales, tanto desde una perspectiva diacrónica, con referencias históricas, como desde un punto de vista teórico abstracto. De igual forma, realizamos una reflexión sobre la diferencia entre transparencia y buen gobierno.

Palabras clave: publicidad, democracia, transparencia, secreto, democracia participativa, democracia inteligente, neoinstitucionalismo.

\begin{abstract}
The principle of transparency has become a core element of democracy, regulated both in state legislation and in the Galician autonomous community. For better understanding and understanding it is necessary to know the epistemological basis of such a principle, what we do in this work in its essential lines, both from a diachronic perspective, with historical references, and from an abstract theoretical point of view. Similarly, we reflect on the difference between transparency and good governance.
\end{abstract}

Keywords: publicity, democracy, transparency, secrecy, participatory democracy, intelligent democracy, neo-institutionalism.

\section{SUMARIO}

1. INTRODUCCIÓN.;- 2. DEL SECRETO A LO PÚBLICO EN EL ESTADO MODERNO.;- 2.1. El nacimiento del Estado Moderno.;- 2.2. Lo secreto en el Estado Absoluto.;- 2.3. La publicidad en el Estado Constitucional.;2.3.1. Nueva mentalidad.;- 2.3.2. Opinión pública libre, control y libertad. 2.3.3. Kant y Brandeis.;- 2.3.4. El caso específico del Parlamento y las resistencias del Gobierno;-. 2.3.5. La llegada de la transparencia.;- 3. DEMOCRACIA PARTICIPATIVA.;- 3.1. La democracia como proceso.;- 3.2. Las exigencias del pluralismo y de la participación: en el camino del gobierno abierto.;- 3.3. Buscando nuevas fronteras: la democracia

Recibido: 10/12/2017. Aceptado: 09/09/2018. 
inteligente.;- 4. LA INFLUENCIA DEL NEOINSTITUCIONALISMO.;- 5. TRANSPARENCIA Y BUEN GOBIERNO: UNA PRECISIÓN ADICIONAL.;- 6. CONCLUSIONES.;- 7. BIBLIOGRAFÍA CITADA.

\section{INTRODUCCIÓN}

Parece oportuno comenzar este número monográfico de la revista Dereito sobre la ley gallega de transparencia con un artículo como este, dedicado a las motivaciones y base epistemológica de sus previsiones, lo que nos obligará a bucear por antecedentes conceptuales y doctrinales que sirvan de contexto adecuado al lector. Como es sabido, las categorías jurídicas no nacen espontáneamente en una pipeta de laboratorio, sino que son producto de una realidad espacial y temporal y de la evolución sociopolítica de la misma. Ello es evidente con relación al principio de transparencia, que se ha entendido de manera diferente con base en esa variable espacial y temporal de la que hablamos.

No resulta fácil perfilar con precisión las ideas y posiciones del pasado que determinan e influyen en las categorías jurídicas del presente, como es la que ahora analizamos. El avance del conocimiento y la progresiva aparición y modificación de las categorías jurídicas es resultado de múltiples factores y variables, de índole diversa (jurídica, sociológica, politológica, económica...), por lo que, en este momento, simplificaremos en parte esta cuestión para adecuarnos a los objetivos de este artículo, inserto en un conjunto de trabajos que comentan los aspectos más relevantes de la LGT.

Esta ley autonómica gallega sobre transparencia responde a las mismas motivaciones de las normas que en los últimos años han regulado dicha cuestión en el Derecho Comparado. Por lo tanto, las reflexiones efectuadas en el presente trabajo son trasladables también a otras leyes. Sin duda, resulta llamativo ver cómo las distintas normas reguladoras de la transparencia y acceso a la información presentan destacada similitud en muchos de sus extremos (quizá el asunto en el que más se han diferenciado es a la hora de establecer el mecanismo y/o órganos de control de la transparencia, lo cual también resulta, por cierto, llamativo). La aprobación de la ley gallega, como ya dijimos en la presentación de esta revista, se enmarca en un conjunto de iniciativas de la Xunta de Galicia para revitalizar la vida democrática, que abarcaban la transparencia, el control y la participación. La idea era reaccionar frente a la corrupción y ante la desafección ciudadana. En su configuración básica se sigue a la ley estatal sobre el particular, lo que era necesario habida cuenta el carácter de básico de ésta en el sistema del Estado Autonómico (disposición final octava de la estatal LETAI) ${ }^{1}$. Con estas normas, la

\footnotetext{
${ }^{1}$ De esta forma, en España la transparencia se ha articulado jurídicamente como un principio. Como es sabido, existen varios tipos de normas jurídicas, que se pueden organizar según distintas variables o criterios, como el origen, la jerarquía, el ámbito de validez o el grado de imperatividad. Con relación a su función, podríamos hacer también diferencias y hablar de normas de comportamiento (como principios y reglas) y normas de organización.
} 
transparencia se integra de manera definitiva en la agenda política y normativa (estatal y autonómica), presidiendo por momentos el discurso público, aunque a veces desgraciadamente con un mero sentido formalista y decorativo.

\section{DEL SECRETO A LO PÚBLICO EN EL ESTADO MODERNO}

Para ordenar las distintas capas de reflexión de este artículo, creemos útil separar una perspectiva diacrónica y otra sincrónica. Empezamos por la primera para ofrecer algunas ideas sobre la evolución a lo largo del tiempo.

Así las cosas, un principio es una norma que persigue una vigencia general que lleva a la abstracción en cuanto a la exigencia de actividad ulterior (J. J. FERNÁNDEZ RODRÍGUEZ, La inconstitucionalidad por omisión. Teoría general. Derecho Comparado. El caso español, Civitas, Madrid, 1998, p. 105). Este rasgo permite una gradación de su cumplimiento (a diferencia de las reglas, que son concretas y cuyo cumplimiento sigue una lógica binaria: se cumplen o no se cumplen). Los principios buscan ser tenidos en cuenta siempre, en toda la legislación, y ser aplicados de forma abierta por los operadores jurídicos. No se satisfarán con una simple actuación concreta del legislador, sino que reclaman actuaciones horizontales, estrategias legislativas permanentes en el tiempo, presencia a la hora de elaborar los distintos sectores del ordenamiento jurídico, y aplicación de las normas a la realidad bajo la inspiración de dicho principio. De todos modos, se detecta una diversidad de significados pues se consideran principios tanto las ideas base de la organización estatal ("principio democrático") como las ideas esenciales de una institución, las normas que incorporan un mandato de optimización y los principios generales para derivar reglas de decisión (F. RUBIO LLORENTE, Derechos fundamentales y principios constitucionales, Ariel Derecho, Barcelona, 1995, XIII y ss.). No vamos a terciar ahora en el debate doctrinal en torno a los mismos, sino que simplemente queríamos llamar la atención sobre la conformación de la transparencia como principio.

No vemos incorrecta esta construcción, aunque tampoco necesaria pues la transparencia podía ser un ámbito material más, objeto de normas jurídicas, y no necesariamente construirse como un tipo de norma determinado (como es un principio). Hacerlo puede generar dudas técnicas, como ¿un principio que incluye un derecho como es el derecho de acceso? No parece tener mucho sentido, pero esta es la conclusión a tenor del contenido de las leyes vigentes.

En la dicción literal del nombre de la ley estatal se habla de transparencia, acceso a la información y buen gobierno. Realmente resulta un tanto impreciso, pues en la conformación de esta temática el acceso a la información es uno de los contenidos de la transparencia (sería la publicidad pasiva), por lo que no debería figurar en el enunciado de la ley. Por lo tanto, la explicación de ese título habrá que hacerla en clave política y sociológica: el legislador quiso subrayar el papel de ese acceso a la información y lo incluyó en el nombre de la ley. En cambio, el título de la ley gallega alude tan solo de transparencia y buen gobierno, por lo que muestra más precisión técnica en sentido jurídico.

Por lo tanto, en la regulación actual el principio de transparencia tiene un contenido diverso, entre el que está el derecho de acceso a la información pública (la publicidad pasiva que acabamos de citar) y la publicidad activa. El derecho de acceso es un derecho público subjetivo, que la doctrina ha visto como fundamental pero que lege lata no lo es. El argumento formal en este caso es claro: las previsiones de este derecho no revisten el carácter de ley orgánica. La regulación constitucional de acceso a los registros y archivos administrativos (art. 105.b Constitución española) está ubicada fuera del Título I, por lo que no es un derecho fundamental sino un mero derecho constitucional (de regulación legal). 


\subsection{El nacimiento del Estado Moderno}

El Estado moderno, que es el Estado propiamente dicho ${ }^{2}$, surge en los siglos XV y XVI gracias a un proceso de concentración del poder y de descentralización del imperio. La evolución de las categorías de unidad y pluralidad permite explicar la aparición del Estado y la superación de las anteriores estructuras medievales.

Como ya hemos sostenido, frente al particularismo feudal el Estado va a imponer la concentración del poder político y su consiguiente secularización ${ }^{3}$. Lo determinante es el cambio en las pautas organizativas de lo público, que se expresa en la citada concentración del poder. Al lado de esta circunstancia nos topamos con otra también de singular importancia: la desaparición del imperio tal y como había sido concebido en la época medieval (el Sacro Imperio Romano Germánico). La pretendida unidad teórica que propugnaba este imperio deja paso a una pluralidad de estados soberanos. En la Edad Media coexisten la idea teórica de unidad del imperio (dirigido por un órgano bicéfalo en la medida en que eran diferentes la potestas en lo espiritual y la potestas en lo temporal -teoría de las dos espadas-); la noción, también teórica, del rey no sujeto a las leyes; y la realidad del ejercicio del poder, diseminado entre distintos señores feudales.

Con el advenimiento del Estado, la unidad y la pluralidad se conciben de diferente manera y se aplican a situaciones absolutamente distintas. Así, por un lado, tenemos unidad, pero dentro de los límites del Estado, y, por otro, encontramos pluralidad, pero desde el punto de vista de las relaciones internacionales. El Estado logra dominar el dualismo que existía entre el poder temporal y espiritual y es capaz de aglutinar el poder en manos del monarca. El rey vence a la Iglesia, al Imperio, y a la autonomía feudal y municipal en medio de un proceso de secularización.

\subsection{Lo secreto en el Estado Absoluto}

La primera versión de este Estado moderno es el Estado absolutista, en el que el rey es titular de la soberanía, por voluntad divina en la concepción de la época. En este primer momento el poder del rey es el poder del Estado, y viceversa. La aparición de la soberanía no es resultado de una construcción abstracta, sino que se produce por claros motivos pragmáticos anudados al intento de superar las guerras civiles de religión que la Reforma había originado en el Viejo Continente. La doctrina de la soberanía refuerza el poder del monarca de tal forma que puede imponerse a las partes enfrentadas (como en Francia tras la guerra de los hugonotes y la ineficacia de los edictos de tolerancia). Bodin escribe en

\footnotetext{
${ }^{2}$ Entendemos que técnicamente Estado solo es el Estado moderno, siendo las formas de organización del poder que le preceden manifestaciones de estructuras diferentes, aunque hay autores que no coinciden con nuestra apreciación (J. J. FERNÁNDEZ RODRÍGUEZ, Los fundamentos del Derecho Constitucional. Derecho, Estado y Constitución, Centro de Estudios Constitucionales del Tribunal Constitucional del Perú, Lima, 2008, pp. 69 y ss.).

${ }^{3}$ Idem, pp. 71 y ss.
} 
este contexto Les six libres de la République (1576) ${ }^{4}$. En cambio, en Inglaterra, Hobbes, con su Leviathan (1651), no trata de mediar entre los bandos enfrentados en la guerra civil, sino que toma partido por el bando absolutista $^{5}$. El poder, en fin, se constituye para salir del estado de guerra.

El ejercicio de este poder acude de forma cotidiana al secreto y a la reserva. El pensamiento de Hobbes ilustra tal concepción. Dicho autor, en el capítulo XXV de la citada obra, considera que las deliberaciones en asamblea presentan muchos inconvenientes, y que por ello "un hombre estará mejor aconsejado oyendo a cada uno" de sus consejeros "por separado, y no reunidos en asamblea" ("a man is better Counselled by hearing then apart, then in an Assembly"), en donde "uno se confunde y aturde con la variedad de discursos que caen sobre él" ("where ... a man is rather astonied, and dazzled with the variety of discourse upon it"). A este respecto, afirma que en los asuntos públicos ocurre con frecuencia que las "deliberaciones deben mantenerse en secreto" ("Deliberations that ought to be kept secret" ${ }^{\prime \prime}$ ). Con el secreto se evitan las desavenencias que aparecen en las asambleas con la deliberación. La discusión pública es lenta, y la divergencia de opiniones da lugar a retrasos en la aplicación de las decisiones. En cambio, el monarca soberano puede recibir consejo de expertos con los niveles de secreto que quiera.

En esta arquitectura del poder, el secreto se muestra como un instrumento para afianzar el poder del monarca. Se alude para ello a la expresión latina arcana imperii, creada por Cornelio Tácito, que la usó para referirse a la política de Tiberio ${ }^{7}$. Esta categoría, que se puede traducir como los secretos del poder, fue recepcionada por Arnoldus Clapmarius en 1605 al publicarse su obra póstuma De arcanis rerum publicarum libri sex. A partir de este momento se difunde entre la publicística alemana incluyendo otros tipos de arcana (como los arcana dominationis, que se ligan a la razón de Estado). Carl Schmitt comenta el concepto de arcana imperii y alude al "plan bien meditado de los gobernantes, que tratan de mantenerse a sí mismos y al Estado, por lo que el poder de los gobernantes, el bien público y el orden y la seguridad públicos" son la misma cosa ${ }^{8}$. Los arcana son planes y prácticas secretos, que ayudan a mantener los iura imperii, o sea, los derechos de soberanía que Bodin enumera como característicos del summun imperium ${ }^{9}$. Los arcana deben otorgar al príncipe el conocimiento necesario para conservar el Estado, conformándose como artes ocultas y secretas que no pueden ser reveladas.

\footnotetext{
${ }^{4}$ En castellano, BODIN, J., Los seis libros de la República, Tecnos, Madrid, 2006.

${ }^{5}$ Idem, pp. 75 y ss.

6 T. HOBBES, Leviathan, Cambridge University Press, Cambridge, 1991, p. 181.En castellano, estas citas pueden verse en Leviatán, Alianza, $2^{a}$ ed., Madrid, 2017, pp. 228229.

${ }^{7}$ TÁCITO, Annales, II, 36 ("arcana imperii temptari"). También en su obra Historiae, I, 4 ("evulgato imperii arcano")

${ }^{8}$ C. SCHMITT, La dictadura, Alianza Editorial, Madrid, 1985, p. 46.

${ }^{9}$ Ibidem, pp. 47-48.
} 
El poder invisible se constituye como un rasgo de esta política fundada sobre la correlación entre soberanía y guerra ${ }^{10}$. Así las cosas, apunta Ruiz Miguel, "el arcanum sirvió como instrumento para mantener una dominación basada en la voluntas"11. El secreto resulta operativo tanto a nivel interno como en el ámbito exterior, donde hay que evitar que los otros estados conozcan las intenciones del propio. La paz interna y la paz exterior están condicionadas al secreto, que es esencial para que el poder político sea eficaz. De esta forma, emplear estrategias secretas aparece como un deber del Estado.

La información se convierte en un elemento de suma relevancia porque es la que permitirá obtener conocimiento. Este supondrá un dominio basado en la razón, que por lo tanto va más allá de la simple voluntad. Bacon es explícito en este orden de cosas, no solo para explicar el dominio que otorga el conocimiento ${ }^{12}$, sino también para mostrar la necesidad de que el gobierno sea "una parte del conocimiento secreta y retirada, en los dos sentidos en que las cosas se consideran secretas: pues unas lo son porque son difíciles de conocer, y otras porque no es conveniente publicarlas" ${ }^{13}$. Sin duda, los escritores políticos se ven atraídos por el tema del secreto, lo que les lleva a aconsejar al gobernante (al príncipe) que guarde materias en el más absoluto secreto para no perder su soberanía y para, también, obtener la veneración de los súbditos por medio del misterio y la impenetrabilidad $^{14}$. Secretos, arcanos o misterios que, como apunta Truyol, se conectan con un saber oculto al servicio de la salus publica ${ }^{15}$.

Por lo tanto, en estas primeras manifestaciones del Estado moderno, el secreto en el funcionamiento de los poderes públicos resultaba conveniente y oportuno en opinión de los distintos autores, coherente con

10 V. SORRENTINO, Il potere invisibile. Il segreto e la menzogna nella política contemporánea, Dedalo, Bari, 2011. In toto.

${ }^{11}$ C. RUIZ MIGUEL, Servicios de inteligencia y seguridad del Estado Constitucional, Tecnos, Madrid, 2002, p. 21.

12 "El dominio que otorga el conocimiento es aún más alto que el dominio sobre la voluntad: porque es un dominio sobre la razón, la fe y el entendimiento del hombre, que son la parte más elevada del espíritu, y que a la propia voluntad dan ley" (F. BACON, El avance del saber, Alianza, Madrid, 1988, p. 70). Esta obra se publica originalmente en 1605.

${ }^{13}$ Idem, p. 210.

${ }^{14}$ Podemos citar a un autor español como Juan Alfonso de Lancina: "El hacer misterio la majestad, es cautela de quien gobierna; se desprecia si mucho se maneja y, aunque más se estime, lo mucho que se mira cansa" (J. A. de LANCINA, Comentarios políticos a los Anales de Cayo Vero Cornelio Tácito, Imprenta Melchor Álvarez, Madrid, 1687, p. 320, CCXIII, núm. 1). En la misma obra se recomienda de manera taxativa al príncipe que "cautela y secreto siempre son buenos" (p. 36, XXII, núm. 3). A su vez, Ludovico Settala afirma en 1627 que "no conviene que el príncipe sea demasiado abierto, la desconfianza, la disimulación y el sigilo son muy útiles para la conservación del Estado" (L. SETTALA, La razón de Estado, Fondo de Cultura Económica, México D. F., 1988, p. 86). Este autor también vive bajo la corona española, pues durante toda su vida Milán fue posesión de España.

${ }^{15}$ A. TRUYOL Y SERRA, Historia de la Filosofía del Derecho y del Estado, tomo II, Alianza, $3^{a}$ ed., Madrid, 1988, p. 134. 
la idea de la razón de Estado ${ }^{16}$. Y ello se entendía en sentido positivo, favorable para la propia comunidad y exigido por la soberanía. No en vano en el siglo XVII se entiende, como señala Spinoza, que "el bien público está exclusivamente dirigido por quien detenta el poder soberano"17.

\subsection{La publicidad del Estado Constitucional}

\subsubsection{Nueva mentalidad}

La situación descrita en el subapartado anterior cambia con el pensamiento ilustrado, en el cual el monarca debe actuar en beneficio del interés general, promoviendo reformas que contribuyan al progreso y felicidad de la nación. La información ya no se concibe como un instrumento de poder en manos del rey, sino que adquiere una cualidad diferente. No podía ser de otra forma si tomamos como válida la divisa que Kant señala de la Ilustración: Sapere aude (iatrévete a saber! O también con una traducción más libre ipiensa por ti mismo!) ${ }^{18}$. El gran esfuerzo de la Encyclopédie de Diderot y D'Alambert ilustra el deseo de progreso de la humanidad por medio de la difusión del saber.

El liberalismo es el movimiento político derivado de la Ilustración. EI liberalismo parte de la libertad del individuo, acota la intervención de los poderes públicos y asume el principio de publicidad de manera palmaria. Así, cuando las revoluciones francesa y norteamericana originan el Estado Constitucional, a finales del siglo XVIII, dicha forma de Estado requiere un espacio público para que la comunidad política que lo conforma participe ${ }^{19}$. La exigencia teórica está firmemente fundada en la medida en que se instaura la soberanía nacional. En este sentido, señala Ruiz Miguel que "si la información es poder y si el poder es del pueblo o nación, la información debe ser accesible a todo el pueblo o nación o al menos al Parlamento" 20 .

Estamos de acuerdo con Aranda Álvarez cuando argumenta que con las concepciones racionalistas que dan lugar al liberalismo político se produce un cambio sustancial en la legitimación del poder. Como ese poder es público, "el conocimiento por parte de los ciudadanos de la acción del

\footnotetext{
${ }^{16}$ En palabras de Meinecke, la razón de Estado es la máximo del obrar político, la ley motora del Estado, que dice al político lo que tiene que hacer, a fin de mantener al Estado sano y robusto (F. MEINECKE, La idea de la razón de Estado en la edad moderna, Centro de Estudios Constitucionales, Madrid, 1983, p. 3).

${ }^{17}$ B. SPINOZA, Tratado teológico-político. Tratado político, Tecnos, Madrid, 4a ed., 2007, pp. $166-167$.

${ }^{18}$ I. KANT, ¿Qué es la Ilustración?, Alianza, Madrid, 1989, p. 81. Este texto procede de 1784. El filósofo de Könisberg toma dicha locución latina de Horacio (Epistularum liber primus, II, 40)

${ }_{19}$ La incipiente democracia moderna se debate inicialmente entre las posturas rousseaunianas de democracia directa y el pragmatismo de la democracia representativa, que es a la postre el que se impone. Incluso, como recuerda Bobbio, a finales del siglo XVIII se contraponía la democracia (representativa) con la democracia de los antiguos (directa) (N. BOBBIO, El futuro de la democracia, Fondo de Cultura Económica, $3^{a}$ ed., México D. F., 2014, p. 15).

${ }^{20}$ C. RUIZ MIGUEL, Servicios de inteligencia..., op. cit., p. 23.
} 
gobierno es fundamental para poder articular su participación en la vida política" ${ }^{\prime 21}$.

\subsubsection{Opinión pública libre, control y libertad}

Resulta evidente que la democracia en sentido moderno se desarrolla desde finales del siglo XVIII acompañada de la idea de publicidad. Esta línea de pensamiento, unida a la libertad de información, sería el antecedente mediato del actual principio de publicidad. Como afirmamos en la presentación de este número extraordinario de Dereito, un buen ejemplo de lo que comentamos es el art. 15 de la Déclaration des droits de l'homme et du citoyen, de 1798, que establecía que la sociedad tiene el derecho a pedir cuentas a todo agente público de su administración ("La société a le droit de demander compte à tout agent public de son administration"). La dación de cuentas es un concepto que lleva a la publicidad.

Al otro lado del Atlántico las ideas son similares. Así, en los Federalist Papers Hamilton y Madison muestran confianza en un futuro gobierno federal por la existencia de un sistema de cheks and balances (frenos y contrapesos) y de accountability (dación de cuentas). Por ejemplo, en el núm. 51 (6 de febrero de 1788) se afirma que "a dependence on the people is no doubt the primary control on the government" (o sea, la dependencia del pueblo es, sin duda, el principal control del gobierno) ${ }^{22}$. Y en el núm. 70 (18 de marzo de 1788) se lee que los ingredientes que proporcionan seguridad en un sentido republicano son "first, a due dependence on the people, secondly, a due responsibility" (es decir, primero, una debida dependencia del pueblo, y segundo, una responsabilidad suficiente -o la responsabilidad necesaria- $)^{23}$. $Y$ en el mismo lugar se afirma que las dos principales garantías del pueblo para que el Ejecutivo ejerza fielmente de poder delegado son el freno de la opinión pública ("the restraints of public opinion") y la oportunidad de descubrir con facilidad y nitidez la conducta indebida de las personas en las que deposita la confianza ("the opportunity of discovering with facility and clearness the misconduct of the persons they trust" ${ }^{24}$.

Se trata de conformar una opinión pública libre que sirva para controlar al poder. En esta tarea la publicidad ayuda, aunque lo que se considera esencial en este momento es lo que hoy llamamos libertades de expresión y de información. Una de las primeras conquistas del constitucionalismo

${ }^{21}$ E. ARANDA ÁLVAREZ, "El marco constitucional de los servicios de inteligencia", en D. NAVARRO BONILLA y M. A. ESTEBAN NAVARRO (coords.), Gestión del conocimiento y servicios de inteligencia, Universidad Carlos III - Boletín Oficial del Estado - Instituto Español de Estudios Estratégicos, Madrid, 2004, p. 157

${ }^{22}$ Citamos por la versión digital en inglés del Proyecto Avalon de la Universidad de Yale: http://avalon.law.yale.edu/18th_century/fed51.asp (consulta en diciembre 2017). La USC editó en gallego O Federalista en 2016 en su colección de Clásicos do Pensamento Universal.

${ }^{23}$ http://avalon.law.yale.edu/18th_century/fed70.asp (consulta en diciembre 2017)

${ }^{24}$ El preámbulo de la LGT, en su comienzo, alude expresamente a los papeles federalistas para ejemplificar la importancia del control de la ciudadanía, aunque se hace sin precisión académica. 
liberal fue el origen de estas libertades, la libertad de imprenta. Así en el art. 11 de la citada Declaración francesa de Derecho del Hombre y del Ciudadano de 1789 se reconoce la libre comunicación de pensamientos y opiniones como uno de los derechos más preciosos del hombre ("la libre communication des pensées et des opinons est un des droits les plus précieux de I' homme"), por lo que todo ciudadano puede "hablar, escribir, imprimir libremente, excepto cuando deba responder del abuso de esa libertad en los casos determinados por la ley" ("parler, écrire, imprimer librement, sauf à répondre de l'abus de cette liberté dans les cas déterminés para la loi"). En la Declaración de Derechos del Buen Pueblo de Virginia de 1776 se afirma que la libertad de imprenta "es uno de los grandes baluartes de la libertad y sólo un gobierno despótico puede restringirla" (apartado XII: "That the freedom of the press is one of the great bulwarks of liberty and can never be restrained but by despotic governments"). En España el tema fue muy relevante en las Cortes de Cádiz y en la Constitución que aprobaron en 1812 (art. 371) ${ }^{25}$, lo que posibilitó una activa prensa política, aunque también se produjeron frecuentes suspensiones de esa libertad de imprenta a lo largo del tiempo. De esta forma, en estos primeros años del Estado Constitucional, queda totalmente asentado el carácter esencial de las libertades de comunicación para el autogobierno democrático y su integración en el proceso público de tales características. Sin embargo, su definitiva preeminencia será un largo proceso, facilitado por la sucesiva conquista de espacios. Como indica Blanco Valdés, "la libertad favorece el avance de la libertad" ${ }^{26}$, lo que permite comprender la sucesiva ampliación de parcelas en el campo de los derechos. Si hubiera que citar a un autor del pasado que defiende de manera argumentada la libertad de expresión e información este no sería otro que el inglés John Stuart Mill, ya en la segunda mitad del XIX, en su obra On Liberty ${ }^{27}$. En fin, la libertad de prensa, la libre discusión y la libertad de reunión son rasgos esenciales del liberalismo.

Sin embargo, pese a todo lo dicho, el secreto y la opacidad del funcionamiento público heredado del Ancien Régime fueron muy difíciles de superar en la práctica, permaneciendo de manera obstinada durante largo tiempo en la realidad del devenir público, sobre todo en el ámbito del ejecutivo y de la administración. Incluso, podría decirse que la regla general en la administración, peso al cambio revolucionario, siguió siendo el secreto, que actuaba con una lógica que no parecía resquebrajarse. Y ello a pesar de otros relevantes posicionamientos que insistían en su defensa de la publicidad, como vemos a continuación.

\footnotetext{
25 J. J. FERNÁNDEZ RODRÍGUEZ, "La libertad de imprenta en las Cortes y en la Constitución de Cádiz de 1812", Dereito. Revista xurídica da Universidade de Santiago de Compostela, vol. 12, núm. 1, 2003, pp. 37 y ss.

${ }^{26}$ R. L. BLANCO VALDÉS, La construcción de la libertad, Alianza, Madrid, 2010, p. 25.

27 J. S. MILL, On Liberty, John Parker and Sohn, Londres, 1859. En castellano, por ejemplo, Sobre la Libertad, Alianza, Madrid, 1997. Para este autor la libertad de expresión se conecta con el interés vital a la autonomía que protege el principio de libertad. El fundamento último del libre intercambio de opiniones es la búsqueda de la verdad.
} 


\subsubsection{Kant y Brandeis}

Para ejemplificar las destacadas posiciones doctrinales que juegan a favor de la publicidad, citamos los casos de los dos autores aludidos en la presentación que realizamos de esta revista. Creemos que ambos sirven de ejemplo de poderosos argumentos favorables a dicha publicidad, construidos desde ámbitos intelectuales diferentes.

El pensamiento de Immanuel Kant es particularmente ilustrativo de lo que estamos diciendo ${ }^{28}$, pues se construye para romper con el Estado de los arcana imperii. Su búsqueda reflexionada de una futura paz perpetua le lleva a enfatizar ciertas categorías, como la de "confianza" (Vertrauen), tanto entre individuos como estados, y la de "veracidad" (Wahrhaftigkeit). Así, la mentira disolverá la confianza: si se dirige contra otros estados, no habrá paz; y si se dirige al interior destruye la legitimidad del poder público. De esta base se deriva que la decisión sobre la guerra debe hacerse mediante una discusión pública, que sea tomada por un órgano público (ahora diríamos un órgano que actúe con transparencia). La libertad de pluma de la que habla el filósofo de Königsberg sirve para defender los derechos de los ciudadanos y ampara la libre discusión pública, que también puede suponer la crítica abierta. Así las cosas, la publicidad cobra singular protagonismo en la obra de Kant. Como apunta Sorrentino, siguiendo a Habermas, "la publicidad es al mismo tiempo principio del ordenamiento jurídico y método esclarecedor"29. Sin publicidad (Publizität) no hay ni justicia ni derecho. He aquí donde Kant crea su famosa "fórmula transcendental del derecho público": "Alle auf das Recht anderer Menschen bezogene Handlungen, deren Maxime sich nicht mit der Publizität verträgt, sind unrecht" ${ }^{\prime 30}$ ("Toda acción relativa al derecho de otros seres humanos cuya máxima no sea conciliable con la publicidad, es injusta"). Esta idea de corte negativo se completa con otra de índole positiva: "Alle Maximen, die der Publizität bedürfen (um ihren Zweck nicht zu verfehlen), stimmen mit Recht und Politikvereinigt zusammen"31 ["Todas las máximas que tienen necesidad de la publicidad (para cumplir sus propósitos), concuerdan conjuntamente con la política y con el derecho"]. El poder público debe ser visible a los ciudadanos y la oscuridad tiene que ser disipada. La publicidad se conecta con la confianza que señalamos antes. Además, que la publicidad sea un "método esclarecedor" significa que es condición de emancipación del pueblo al librarle de los perjuicios heredados.

\footnotetext{
${ }^{28} \mathrm{~V}$. Sorrentino compara los pensamientos de Hobbes y Kant para mostrar que son dos dispositivos conceptuales contrapuestos y concluir que el primero está fundado sobre la correlación entre principio de soberanía, guerra y secreto; y el segundo sobre el nexo existente entre la publicidad del poder, el derecho al uso público de la razón y la crítica de la mentira (V. SORRENTINO, "Discusión púbica y transparencia del poder en Hobbes y Kant", Laguna: Revista de Filosofía, núm. 36, 2015, p. 21).

${ }^{29}$ Idem, p. 30.

${ }^{30}$ I. KANT, Zum ewigen Frieden. Ein philosophischer Entwurf, Friedrich Nicolovius, Königsberg, 1795, p. 93.

${ }^{31}$ Idem, p. 103.
} 
El segundo ejemplo en defensa de la publicidad que queremos mostrar al lector en este subaparatado, igualmente muy conocido, es del otro lado del océano. Así, desde diferentes postulados, pero que también han pasado a la posteridad, el magistrado estadounidense Louis D. Brandeis afirmó que "sunlight is said to be the best of disinfectants" (o sea, que "la luz del sol es el mejor desinfectante") ${ }^{32}$. Con esta frase Brandeis quería sintetizar la importancia de poner la información a disposición del público. En concreto, estaba criticando el poder de los grandes grupos financieros.

\subsubsection{El caso específico del Parlamento y las resistencias del Gobierno}

Pero en donde la publicidad cobra mayor fuerza y procedencia en el devenir del Estado es en el Parlamento, una institución en la que la publicidad resulta esencial, al menos en su construcción teórica. Carl Schmitt disecciona con precisión las características del Parlamento, aunque para criticarlo, y sentencia que la publicad y la discusión son las que dan sentido al Parlamento ${ }^{33}$. El Parlamento es "un lugar en donde se realiza una discusión pública de las opiniones políticas (...) encuentra en la discusión pública la verdad razonable y la norma justa (...) la publicidad de las deliberaciones es el nervio de todo el sistema" ("Das Parlamente ist (...) an welchem eine öffentliche Diskussion der politischen Meinungen stattfindet $(\ldots)$ in öffentlicher Diskussion die vernünftige Wahrheit und die gerechte Norm findende Parlament (...) Die Öffentlichkeit der Verhandlungen ist der Kern des ganzen Systems") ${ }^{34}$. Sin duda, el Parlamento, en cuanto foro de debate político, tienen en la publicidad su característica esencial.

A pesar de esta rotunda construcción dogmática, la realidad práctica, de nuevo, no fue tan meridiana al mostrar relevantes resistencias en una valoración global de los sistemas públicos. No cabe duda de que a lo largo del siglo XIX y XX, el asentamiento de la publicidad se ve atemperado porque se entendía que resultaba conveniente que existiera un relevante número de parcelas de secreto en el Estado Constitucional. La dinámica del Estado Constitucional está en parte supeditada a concretar el modelo de relación entre publicidad y secreto. En este sentido, la institución del gobierno y de la administración son las que más se han resistido a la publicidad en el Estado Constitucional, y anudadas a las mismas la burocracia del Poder Ejecutivo. El argumento de estas resistencias se

32 La cita procede del capítulo cinco de su obra Other People's Money, and how the Bankers use it, Frederick A. Stokes Company, Nueva York, 1914, p. 92. El capítulo cinco se titula "What Publicity Can Do". Esta obra es una colección de ensayos editados conjuntamente como libro en la fecha indicada, 1914, aunque antes ya habían aparecido en la revista política Harper's Weekly. A Journal of Civilization. Brandeis es también famoso por construir doctrinalmente el derecho a la privacidad en 1890, con su colega Warren.

33 "Todos los órganos y normas específicamente parlamentarias cobran su sentido sólo por la discusión y la publicidad" (C. SCHMITT, Sobre el parlamentarismo, Tecnos, Madrid, 1996, p. 5).

${ }^{34}$ C. SCHMITT, Verfassungslehre, Duncker \& Humblot, 1928, pp. 315-316. En castellano, Teoría de la Constitución, Alianza, Madrid, 1982, pp. 303-304. 
basaba en su saber técnico y en el secreto profesional que sujetaba al burócrata. También el entendimiento de la categoría de secreto de estado (o secreto oficial) se hace manera excesivamente amplia ${ }^{35}$. Como señala Cotino, "el secretismo era una muestra más de la superioridad de la administración frente a los administrados" ${ }^{\prime 36}$. En este sentido, Weber también recordó que el "gobierno burocrático es, por su misma tendencia, un gobierno que excluye la publicidad"17. Los datos históricos evidencian que la razón de estado propició tentaciones de uso abusivo por parte de los gobernantes, con el secreto como "instrumento de dominación por parte del poder público", un fin en sí mismo ${ }^{38}$.

Incluso, la institución que es en sí misma un espacio público, como hemos dicho, el Parlamento, también ha mantenido parcelas de secreto, como en los debates de las comisiones o, en algún supuesto, del pleno. El cambio definitivo (al menos teórico) vendrá tras la II Guerra Mundial, que es a lo que pasamos a referirnos, también de manera breve.

\subsubsection{La Ilegada de la transparencia}

En el epígrafe anterior hemos hecho un rápido recorrido por la idea de publicidad. Es necesario ahora subrayar que publicidad y transparencia no son lo mismo. La transparencia tiene un contenido diverso, con elementos objetivos (publicidad activa) y subjetivos (derecho de acceso), al que se suma un sistema de garantías, y, sobre todo, una dimensión sociológica que pretende crear una verdadera cultura de transparencia. Dicha cultura debe cambiar la relación de la ciudadanía con el poder público y la actitud de este último con relación a aquella. La simple publicidad no tenía estas implicaciones que ahora han aflorado en el moderno concepto de transparencia, por lo que la consideramos como un antecedente mediato.

De este modo, la publicidad propia del Estado Constitucional, el desarrollo de los derechos a la libertad de expresión e información y las tendencias neoinstitucionalistas (a las que nos referiremos más abajo) propiciarán el nacimiento de la categoría de transparencia tal y como la conocemos ahora.

Tras la II Guerra Mundial, como reacción a la propia guerra, se abre un período de reconocimiento de los derechos humanos en el Derecho Internacional, entre los que se encuentra la libertad de expresión e información. En este sentido, en el ámbito de Naciones Unidas, tenemos el

\footnotetext{
${ }^{35}$ Sobre ello puede verse en castellano S. SÁNCHEZ FERRO, El secreto de estado, Centro de Estudios Políticos y Constitucionales, Madrid, 2006.

${ }^{36}$ L. COTINO HUESO, "Del «deber de publicidad» de Brandeis al «open government» de Obama. Regulación y control de información pública a través de las nuevas tecnologías", en G. ESCOBAR ROCA, La protección de los derechos humanos por las defensorías del pueblo, Dykinson, Madrid, 2013, p. 860.

37 M. WEBER, Economía y sociedad, Fondo de Cultura Económica, México D. F., 1964, p. 746.

${ }^{38}$ H. W. MORERA DE LA VALL, Secretos de Estado y Estado de Derecho: régimen jurídico de los secretos oficiales en España, Atelier, Barcelona, 2007, p. 47. En el mismo lugar, esta autora entiende que en cualquier caso el equilibrio entre secreto y transparencia resulta difícil, sobre todo por la necesidad de supervivencia del orden político constitucional.
} 
art. 19 de la Declaración Universidad de Derechos Humanos de 1948 y el art. 19.2 del Pacto Internacional de Derechos Civiles y Políticos de 1966; en el seno del Consejo de Europa hay que citar el art. 10 del Convenio Europeo de Derechos Humanos de 1950; y en la Organización de Estados Americanos la referencia es el art. 13.1 de la Convención Americana de Derechos Humanos de 1969. A su vez, en todas las constituciones democráticas se contemplan estas libertades. La doble vertiente que se les atribuye, individual e institucional, refuerza su papel en el sistema público como garantía de una opinión pública libre y del pluralismo político y social.

En 1993 Naciones Unidas (Comisión de Derechos Humanos, actualmente Consejo de Derechos Humanos) creó una Relatoría Especial para la Libertad de Opinión y Expresión, que ha servido para profundizar en el derecho de acceso a la información, que se considera un derecho fundamental y un pilar de las democracias ${ }^{39}$. Por lo tanto, es el acceso lo que primero se defiende jurídicamente. También trabajaron en la promoción de este derecho el Representante de la OSCE sobre la Libertad de los Medios de Comunicación Social y el Relator Especial de la OEA sobre la Libertad de Expresión, que han actuado conjuntamente con el relator de la $\mathrm{ONU}^{40}$. La Unión Europea ha sido igualmente un actor clave para el reconocimiento del derecho de acceso, aprobando el Reglamento 1049/2001, de acceso a los documentos del Parlamento Europeo, Consejo y Comisión, y previendo en la Carta de Derechos Fundamentales tal derecho de acceso a los documentos (art. 42). En el marco del Consejo de Europa, sobresale el Convenio número 205, sobre el Acceso a los Documentos Públicos, de 2008. El Tribunal Europeo de Derechos Humanos lo fue reconociendo progresivamente.

Este escenario jurídico era el propicio para dar ese salto adicional que supuso el principio de transparencia aplicable a los poderes públicos. La irrupción de la Sociedad de la Información y el gran desarrollo de la tecnología digital ayudaron de manera importante en las dos últimas décadas del siglo XX. De este modo, los países más avanzados democráticamente fueron los primeros en aprobar normativa específica de acceso a la información pública. Así, los países escandinavos (Finlandia, 1951; Dinamarca, 1970; Noruega, 1970; con el precedente de Suecia de 1766) y Estados Unidos (1966). A finales del siglo XX se había generalizado a nivel mundial las previsiones normativas de transparencia y acceso a la información. España estuvo en la cola de este proceso: la parca previsión constitucional del art. 105.b solo estaba desarrollada, y de manera también encorsetada, por la ya derogada Ley 30/1992. Habrá que esperar al siglo XXI para que nuestro país se incorpore al nutridísimo

39 La web de esta relatoría es http://www.ohchr.org/SP/Issues/FreedomOpinion/Pages/OpinionIndex.aspx

40 Sobre esta evolución en el ámbito internacional puede verse el XIII Informe sobre Derechos Humanos de la Federación Iberoamericana de Ombudsman, titulado Transparencia e información pública, dirigido por G. ESCOBAR ROCA, y editado por Trama en Madrid en 2015, pp. 23 y ss. 
grupo de países que cuentan con una ley ad hoc de transparencia ${ }^{41}$, a través de la LETAI. La LGT sigue la senda que marca la LETAI y proclama de manera genérica que "toda la información pública es accesible y relevante, y toda persona tiene acceso libre y gratuito a la misma", con las excepciones que marca la ley (at. 2.a LGT).

De todos modos, este mapa de previsiones normativas no ha acallado críticas basadas en la realidad del ejercicio del poder. Bobbio habla de la supervivencia de un poder invisible, que ha convertido en una falsa promesa de la democracia real, la eliminación del mismo ${ }^{42}$.

\section{LA DEMOCRACIA PARTICIPATIVA}

En el epígrafe anterior hemos hecho un recorrido diacrónico por diversas situaciones e ideologías históricas que nos han permitido ver la base epistemológica para las actuales leyes de transparencia. Hacemos ahora una aproximación sincrónica, de corte teórico-abstracto, para completar el argumentario por nosotros esgrimido.

\subsection{La democracia como proceso}

En otro lugar hemos sostenido que la democracia es un proceso continuo de control del poder que se articula a través de diversos mecanismos ${ }^{43}$, y que en todo caso estará basado en la ciudadanía. El más llamativo de todos esos mecanismos de control son las elecciones, aunque la democracia no se limita a las cuestiones electorales y va más allá al englobar al pluralismo, la participación y elementos axiológicos que la convierten en un auténtico principio de convivencia. La democracia se nos muestra, así, como cultura, la cultura democrática. Y en ese mismo lugar, reflejamos como se produce un salto desde la democracia como sistema a la democracia como valor. Este control del poder reclama igualmente la participación ciudadana en la toma de decisiones.

Desde este entendimiento, los derechos fundamentales se incorporan al núcleo esencial de la democracia para dotar a las personas de facultades que se derivan de su propia dignidad, y que les permitirán ejercer ese control y participar en la construcción de las políticas públicas y en su aplicación.

Pues bien, la transparencia del sector público juega de manera definitiva a favor de la buena marcha del citado proceso democrático. El control y la toma de decisiones que hemos indicado en el concepto de democracia solo pueden ser efectivos con transparencia pública, que se revela como verdadera condicio sine qua non. En el preámbulo de la derogada Ley

\footnotetext{
${ }^{41}$ Sobre esta expansión de la leyes de transparencia puede verse el documento de E. GUICHOT REINA, "Transparencia y acceso a la información pública en España: análisis y propuestas legislativas", en http://www.fundacionalternativas.org/public/storage/laboratorio_documentos_archivos/a 1d04f2c5f4e94e441966c1b79f39fa3.pdf (consulta en noviembre 2017).

${ }^{42}$ N. BOBBIO, El futuro de la democracia, op. cit., pp. 16 y 36 y ss.

${ }^{43}$ FERNÁNDEZ RODRÍGUEZ, J. J., Lo público y lo privado en Internet. Intimidad y libertad de expresión en la Red, Universidad Nacional Autónoma de México, México D. F., 2004, p. 199.
} 
gallega 4/2006, de transparencia y buenas prácticas en la Administración pública, se lee que resulta necesario "ofrecer a la ciudadanía mecanismos de control a través de la transparencia administrativa, que se configura, entonces, como un fundamento esencial del sistema democrático moderno". La LGT cita la palabra "control" 26 veces, lo que la convierte en uno de sus leitmotiv, además de considerar en el punto 3 de su preámbulo que existe una "creciente exigencia ciudadana de control público de la actividad de las instituciones".

La opacidad y el secreto son un obstáculo insalvable que impiden calificar un sistema donde imperen de democrático. En esta línea, Bobbio sentencia que "la democracia se puede definir de muchas maneras, pero no hay definición que pueda excluir de sus connotados la visibilidad o transparencia del poder" ${ }^{44}$. Como también se dice en el citado y derogado preámbulo de la Ley 4/2006, la imagen de opacidad e inaccesibilidad de la Administración genera "desconfianza en la ciudadanía". Frente a ello, la transparencia facilita que la sociedad asuma un papel activo en la vida administrativa", mientras que "una opinión pública informada contribuye a definir y realizar acciones públicas respetuosas con el interés general".

De este modo, la idea de transparencia se ha convertido en un elemento imprescindible en la noción de democracia y, por ende, en la calidad de la misma. Como hemos visto supra, la idea de publicidad ya estaba presente, de una u otra forma, en los orígenes de la democracia moderna. Sin embargo, el sentido actual de la transparencia y del acceso a la información es algo diferente, con un componente objetivo y obligatorio que nos lleva a interpretar que estamos ante una situación nueva. Por eso afirmamos que la transparencia se ha incorporado a la democracia. También García Morales ve este salto cualitativo cuando señala que "las nuevas obligaciones de publicidad activa y otros cambios en el régimen de acceso a la información pública están creando una cultura favorable respecto a la publicidad de la información, así como a la hora de empoderar al ciudadano"45. El exponente prototípico de este papel proactivo y obligatorio del gobierno y la administración, posibilitado por la irrupción de la tecnología digital, es la publicidad activa.

En este sentido, hay que traer a colación el concepto de rendición de cuentas, que nos ha llegado de la ya citada expresión inglesa accountability, sobre todo a través del ámbito empresarial. La rendición de cuentas hace referencia a la responsabilidad de un cargo, que somete sus "resultados" de manera proactiva a evaluación pública, manifestando así su compromiso. Es, por lo tanto, una categoría diferente a la transparencia, pero muy conectada a la misma, pues ésta determina la eficacia de aquélla. Y también una categoría imprescindible en el proceso de control que, como estamos diciendo, supone la democracia.

\footnotetext{
${ }^{44}$ N. BOBBIO, El futuro de la democracia, op. cit., p. 16.

${ }^{45}$ M. J. GARCÍA MORALES, Transparencia y rendición de cuentas de las relaciones de cooperación intergubernamental en el Estado autonómico, Generalitat de Catalunya, Barcelona, 2017, p. 29.
} 
De igual modo, no hay que olvidar que los ideales de transparencia se refuerzan, como señala Almonacid, ante el avance de la desconfianza y la desafección ${ }^{46}$. Está clara la conexión de la necesidad de mayor transparencia para frenar a la corrupción. De nuevo como apunta Almonacid: "Cuanto más observados nos sentimos mejor actuamos, de ahí la importancia de observar atentamente a los poderes públicos, para forzar con nuestra observación su mejor conducta"47. Por estas razones, la LETAI fue una ley largamente esperada "como instrumento esencial de profundización y regeneración democrática" ${ }^{48}$.

\subsection{Las exigencias del pluralismo y de la participación: en el camino del gobierno abierto}

Dos de los elementos nucleares de la democracia reclaman de manera ineluctable la aplicación del principio de transparencia al poder público. Sin él, el pluralismo y la participación serían meramente cosméticos y no reales ni efectivos.

La participación es esencial en la democracia, tanto en el marco de la democracia directa como en el de la democracia representativa. Casi huelgan los comentarios al respecto. En el preámbulo de la derogada Ley gallega 4/2006, de transparencia y buenas prácticas en la Administración pública, se leía que "la participación de la ciudadanía en los asuntos públicos se conforma hoy como un elemento fundamental". En este sentido, el art. 4.2 del Estatuto de Autonomía de Galicia, siguiendo al art. 9.2 de la Constitución española, encarga a los poderes públicos "facilitar la participación de todos los gallegos en la vida política, económica, cultural y social". En el entendimiento de la democracia participativa ello, incluso, se intensifica para reclamar una participación permanente y de fondo. La LGT usa "participación" 16 veces, insistiendo en la misma al recoger como principio rector el principio de participación ciudadana (art. 2.c LGT). También la idea de accesibilidad universal se ubica en esta línea (art. 2.b LGT). Además, en Galicia existe la Ley $7 / 2015$, de iniciativa legislativa popular y participación ciudadana en el Parlamento de Galicia ${ }^{49}$, que desarrolla el art. 13.1 del Estatuto de Autonomía.

El pluralismo hará que esa participación sea heterogénea al provenir de diferentes sectores. En efecto, el pluralismo persigue regir en toda la sociedad, en todas sus manifestaciones y aspectos (ideología, cultura, economía, etc.). La vigente Constitución recoge el pluralismo como un

\footnotetext{
46 V. ALMONACID MENDIETA, "El largo camino hacia la transparencia en los ayuntamientos españoles", El consultor de los ayuntamientos, núm. 18, Especial Transparencia en la actividad municipal, 2015, p. 1985.

${ }^{47}$ Ibidem.

48 E. GUICHOT, "Presentación", en E. GUICHOT (coord.), Transparencia, acceso a la información pública y buen gobierno, Tecnos, Madrid, 2014. p. 15

49 Por medio de ella se deroga la Ley $1 / 1988$, de iniciativa legislativa popular ante el Parlamento de Galicia. La previsión más relevante de la Ley $7 / 2015$ es la de fijar en 10 mil las firmas necesarias para la iniciativa legislativa popular. Además, prevé participación popular en la elaboración de las leyes, en el control del gobierno y en el ejercicio del derecho de petición.
} 
valor superior del ordenamiento jurídico (art. 1.1), exige a los medios de comunicación públicos respetar el pluralismo de la sociedad (art. 20.3), constitucionaliza partidos políticos (art. 6), sindicatos y asociaciones de empresarios (art. 7), y prevé el derecho de asociación (art. 22).

La evolución de estas categorías llega al concepto de open government o gobierno abierto, que presenta un sentido sinérgico y prospectivo: transparencia, participación y colaboración. En este sentido, ya se ha hecho famosa la defensa de Obama de este tipo de gobierno, cuando accedió a la presidencia de Estados Unidos en 2009. En este orden de cosas, también hay que citar la denominada Alianza para el Gobierno Abierto (Open Government Partnership), que desde 2011 integra gobiernos que trabajan en esa línea. Sus elementos clave son cuatro: transparencia, participación ciudadana, rendición de cuentas y tecnología e innovación.

Como hemos defendido, "ya no basta para gobernar con cumplir meramente el principio de legalidad, hay que ir más allá para lograr el desarrollo social" ${ }^{\prime 50}$. Esto es lo que pretende otra idea, la de gobernanza, que alude a la eficacia y calidad de una actuación pública integradora de los agentes político-sociales. La traducción jurídica de estas cuestiones es el derecho a la buena administración ${ }^{51}$.

\subsection{Buscando nuevas fronteras: la democracia inteligente}

Como afirma Bobbio, "para un régimen democrático estar en transformación es el estado natural; la democracia es dinámica y el despotismo es estático" ${ }^{\prime 52}$. La historia corrobora esta realidad evolutiva, que creemos que debe seguir hacia el futuro de la mano de la nueva impronta que supone el principio de transparencia. Con una verdadera implantación de la transparencia, el poder público cambia su actitud respecto a la ciudadanía, en la que debe confiar y aprovechar para mejorar las políticas. Incluso, vislumbramos nuevos conceptos, como es este que ahora proponemos de democracia inteligente. Permítasenos volver a efectuar con brevedad otra reflexión diacrónica.

Como es conocido, la democracia representativa se impuso en el debate práctico (y de las ideas) a la democracia directa. Resultó ser, sin duda, más pragmática, y también menos exigente para la ciudadanía en la

50 J. J. FERNÁNDEZ RODRÍGUEZ, Defensorías del pueblo en España: una visión prospectiva, Universidad de Alcalá, 2014, p. 94.

${ }^{51}$ El art. 41.1 de la Carta de Derechos Fundamentales de la Unión Europea reconoce este derecho y lo conceptúa así: "Toda persona tiene derecho a que las instituciones y órganos de la Unión traten sus asuntos imparcial y equitativamente y dentro de un plazo razonable". En el siguiente párrafo se indica que tal derecho incluye el derecho a ser oído, el acceso al expediente y la obligación de motivación de las decisiones de la administración. También recoge este derecho la Ley gallega $1 / 2015$, de 1 de abril, de garantía de la calidad de los servicios públicos y de la buena administración. En su art. 3 se habla del derecho de la ciudadanía a "una administración eficaz, que gestione sus asuntos con imparcialidad, objetividad y dentro del marco temporal establecido", lo que se concreta en recibir un trato respetuoso, atención, identificar al responsable o presentar sugerencias y quejas.

${ }^{52}$ N. BOBBIO, El futuro de la democracia, op. cit., p. 15. 
medida en que el peso del funcionamiento del sistema recae en el representante, que incluso llega a ser profesional en ese ámbito. Para el correcto servicio al interés general resulta recomendable seguir las ideas de Stuart Mill, que entendía que las elecciones deben tener un valor selectivo, es decir, debemos obtener "buenos representantes" 53 .

La democracia representativa evoluciona a lo largo de los siglos XIX y XX de una forma muy intensa. Así, de un sufragio censitario se pasa al sufragio universal masculino. Y después, se llegará al sufragio universal también femenino. Los derechos sociales igualmente completan y enriquecen este panorama de la representación, donde la justicia material encuentra su campo de juego. Sin embargo, las voces críticas con la democracia retumban a veces con intensidad ${ }^{54}$.

En el último tercio del siglo $X X$ se intensifica la crisis de la democracia representativa y del parlamentarismo, que se extiende a los partidos, aunque sigan desempeñando un rol relevante. Esta crisis es también crisis de valores. Y la doctrina busca respuestas. Es el caso de la democracia deliberativa de Habermas, en la que los parlamentos generan una racionalidad dialógica en el control de las políticas públicas ${ }^{55}$. Martí considera que el modelo de democracia deliberativa se caracteriza por ocho principios, entre los que está la publicidad ${ }^{56}$.

El desarrollo y asentamiento de la tecnología digital evidencia las limitaciones de la representación tradicional, presionada por la propia corrupción. Los intermediarios sociales se han, en parte, difuminado, o, al menos, han menguado (partidos, prensa, sindicatos, parlamentos...). Para llenar este vacío, en cierto modo provocado por la desafección, surge una nueva arquitectura de participación nacida de la Red que lo impregna todo. $Y$ se marcan diferencias entre la vieja y la nueva política: hacer las cosas para los ciudadanos vs. hacer las cosas con los ciudadanos.

La democracia participativa, que lleva décadas estudiándose, se revitaliza en los últimos tiempos para intentar sobreponerse a la(s) citada(s) crisis. Citábamos supra a Bobbio, que recuerda que a finales del siglo XVIII se contraponía la democracia (representativa) a la democracia de los antiguos (directa). Ahora, tal vez, haya que reformular esta afirmación, y contraponer la democracia actual (participativa) a la democracia de los "antiguos modernos" (la representativa).

Pues bien, apelando a ese movimiento consustancial a la cultura democrática, vislumbramos una democracia inteligente, que tenga un sentido relacional y conecte derechos fundamentales de diversas generaciones con los aspectos sociales y políticos, la ecología, la inclusión

\footnotetext{
53 J. S. MILL, Considerations on Representative Government, Parker, Son and Bourn, Londres, 1861.

${ }^{54}$ Sobre la insatisfacción de la democracia vid. J. L. MARTÍ, La democracia deliberativa, Marcial Pons, Madrid, 2006, pp. 11 y ss.

55 J. HABERMAS, Theorie des Kommunikativen Handelns, Suhrkamp, Frankfurt, 1981. En castellano, Teoría de la acción comunicativa, Taurus, Madrid, 1987.

56 J. L. MARTÍ, La democracia deliberativa, op. cit., p. 316. Los otros principios son: argumentación, procedimiento colectivo, inclusión, procedimiento abierto, procedimiento continuo, libertad e igualdad de los participantes.
} 
y la tolerancia. Una democracia inteligente que tiene que ir más allá de los intereses económicos y del mero individualismo acumulador. Se trata de buscar una igualdad estructural, basada en un equilibrio entre seguridad y libertad, con compromiso medioambiental, que aproveche las fortalezas del espacio neopúblico ${ }^{57}$ originado en el mundo digital, y que implemente elevadas cotas de transparencia. Esta democracia debe incorporar igualmente ese sentido de proceso continuo de control del poder del que hemos hablado, desde el pluralismo y la participación, pero también con elementos nucleares inquebrantables, referidos al núcleo esencial de los derechos fundamentales, que debe servir de límite para incorrectos entendimientos, por ejemplo, de la multiculturalidad. Una democracia inteligente que reclama compromiso ciudadano y fortalecimiento de sus valores, educación material y sustantiva en esa línea. En fin, un sentido de democracia que necesita imperiosamente y de manera continua de una transparencia real y efectiva, que vincule poderes públicos y personas en un paradigma colaborador y de confianza mutua. Se requiere, por lo tanto, de una auténtica cultura de transparencia.

Esta verdadera cultura de transparencia, de la mano de un evolucionado entendimiento de la democracia, debe superar un hábil engaño: el de la información sin más. La información sin más y la mera acumulación de datos no significan transparencia, incluso pueden ser perjudiciales para la dinámica democrática. Me refiero, con García Morales, a que "la sobreabundancia de información solo puede conseguir desorientar y desanimar al ciudadano en un océano de datos, en lugar de empoderarlo para participar en los asuntos públicos" ${ }^{\prime 58}$. Los datos por sí solos no proporcionan conocimiento útil en el control del poder. La democracia inteligente tiene que servir para evitar un entendimiento incorrecto de la transparencia, absoluto, de sobreinformación que no conduce a la verdad ni forma a la opinión pública. Desde un punto de vista filosófico, ByungChul Han critica de manera ardua la "sociedad de la transparencia", que abarca todos los ámbitos y que se deriva de la sociedad de la exposición. La transparencia, para él, "es una coacción sistémica que se apodera de todos los sucesos sociales" 59 , identificada con la "sociedad positiva", que hace perder la singularidad a las cosas, reducidas como los propios sujetos a mera mercancía. Si no estás expuesto, no existes, con lo que la comunicación se anestesia, irreflexiva, y la transparencia se une "a un vacío de sentido" ${ }^{\prime 60}$.

\footnotetext{
57 J. J. FERNÁNDEZ RODRÍGUEZ, "Lo neopúblico: un nuevo espacio en Internet para el ejercicio de los derechos fundamentales", en PÉREZ ROYO, Javier; URÍAS MARTÍNEZ, Joaquín; CARRASCO DURÁN, Manuel (editores), Derecho Constitucional para el siglo XXI. Actas del VIII Congreso Iberoamericano de Derecho Constitucional, vol. I, Aranzadi, Pamplona, 2006, pp. 1233 y ss. Hay que tratar de mitigar los elementos negativos de la tecnología digital, desarrollando sus fortalezas y posibilidades para la democracia, que pasan por comunicar, informar, interactuar, editar, opinar o intercambiar. Un abanico amplísimo que sólo con adecuada conciencia ciudadana podremos aprovechar realmente.

${ }^{58}$ M. J. GARCÍA MORALES, Transparencia y rendición de cuentas..., op. cit., p. 73.

${ }^{59}$ B-C. Han, La sociedad de la transparencia, Herder, Barcelona, 2013, p. 12.

${ }^{60}$ Idem, p. 32.
} 
Frente a este riesgo real, nosotros apostamos por una democracia en renovación continua para ganar cualidad y despojarse de lo cuantitativo que sea innecesario. Se trata de abrir espacio al debate real y reflexivo, desacelerado, que permita razonar el auténtico interés general y la verdad, sin las censuras de lo "políticamente correcto". Precisamente, a favor de la verdad juega el principio de veracidad que existe en las leyes de transparencia: toda la información pública será cierta y exacta, procediendo de documentos de los que se verificó su autenticidad, fiabilidad, integridad, disponibilidad y cadena de custodia (art. 2.d LGT).

En suma, la democracia inteligente va mucho más allá del aludido gobierno abierto, desarrollándose en diversos equilibrios en el escenario del respeto ambiental: público y privado, seguridad y libertad, intereses de grupos e intereses individuales (la democracia aparece y se desarrolla con un fuerte enfoque individualista, aunque progresivamente los grupos asumen un mayor protagonismo), unidad y pluralidad, homogénea en los valores esenciales (irrenunciables) y plural en el resto.

\section{LA INFLUENCIA DEL NEOINSTITUCIONALISMO}

Llegados aquí aún creemos necesario aportar otro punto de vista sobre la línea epistemológica que estamos siguiendo. Al margen de lo dicho, y actuando de manera paralela (por decirlo de algún modo), la línea inmediata de pensamiento que se conecta con el actual entendimiento del principio de transparencia es la corriente politológica del neoinstitucionalismo ${ }^{61}$.

Cuando aparece la Ciencia Política moderna los estudios institucionales son los habituales (siglo XIX), con evidentes elementos estructuralistas. Sin embargo, tras la II Guerra Mundial el objeto de análisis se centra en componentes individualistas, como son el conductismo o la elección racional, que presuponen que los individuos actúan autónomamente sin ser constreñidos por las instituciones. No obstante, en las dos últimas décadas del siglo XX se renuevan los estudios sobre las instituciones, sobre todo por medio de influyentes autores, como March, Olsen ${ }^{62}$,

\footnotetext{
${ }^{61}$ Ello nos obliga a efectuar un par de reflexiones contextuales para aproximarnos correctamente a esta cuestión. La primera precisión que debemos llevar a cabo, en una revista jurídica como Dereito, es el diferente sentido de los conceptos empleados en Derecho y en Ciencia Política. En lo que ahora nos puede interesar, encontramos diferencias en el sentido de lo "normativo" y lo "positivo". Así en Ciencia Política lo "normativo" se refiere al deber ser; y lo "positivo" al ser, o sea, a la descripción de una realidad dada. En cambio, en Derecho lo "normativo" alude a la norma jurídica y a sus características; y lo "positivo" a lo previsto en una norma en vigor (y normalmente escrita). En cambio, el sentido de "institución" sí presenta cierta conexión entre ambas ciencias, al referirse a la dinámica y al contexto en el que se desarrolla, por lo que su estudio va más allá de la mera descripción de su normativa reguladora. La "institución" en Ciencia Política incorpora no solo reglas sino también rutinas, además de ser reflejo de las fuerzas sociales.

62 J. G. MARCH, y P. OLSEN, "The new institutionalism: organizational factors in political life", American Political Science Review, núm. 78, 1984, pp. 738-749. De los mismos autores, Rediscovering Institutions, Free Press, Nueva York, 1989.
} 
Peters $^{63}$, Hall o Taylor $^{64}$. Este neoinstitucionalismo se vuelve heterogéneo ${ }^{65}$, extendiéndose a otras ramas del saber más allá de la Ciencia Política. Así nos encontramos con la nueva economía institucional o con el institucionalismo sociológico. No cabe duda de que limitarse a la conducta individual es insuficiente para explicar lo que sucede en la dinámica del poder. Los individuos hacen sus propias elecciones, pero en el marco de los parámetros fijados por los valores institucionales dominantes, lo que determina un comportamiento normativo (en sentido politológico). Las instituciones moldean las preferencias de los individuos y manipulan los incentivos.

Este nuevo institucionalismo también se relaciona con los estudios de elección racional. Tradicionalmente, como hemos dicho, los análisis de elección racional no se ubicaban en el institucionalismo sino en enfoques individualistas. El cambio de enfoque determina que aparezca un institucionalismo de elección racional y un institucionalismo transaccional ligado, como apunta Caballero, al análisis político de costes de transacción ${ }^{66}$. Los individuos se integran en instituciones y aceptan y observan sus reglas. Las instituciones aparecen como "estructuras de cooperación voluntaria que resuelven problemas de acción colectiva y benefician a todos los afectados ${ }^{\prime 67}$, lo que hace emerger un elemento funcionalista. La actividad política implica efectuar transacciones, que suponen costes. Las instituciones economizarán dichos costes y estructurarán los incentivos. El nuevo institucionalismo transaccional "emerge a partir del institucionalismo de elección racional" y asume "que la información es costosa y que los mercados políticos están plagados de costes de transacción" ${ }^{\prime 68}$.

Pues bien, en este marco conceptual y metodológico, el sistema político neoinstitucional necesita la vigencia efectiva del principio de transparencia. La elección racional en política requiere información, y esta se provee por medio de la transparencia del sector público. La información asume un papel central en la política y en las organizaciones políticas. Pero también en el devenir cotidiano de la comunidad en su relación con el sector público. La dinámica institucional está en la raíz del comportamiento político, que por tanto es colectivo, y no individual, necesitando información y transparencia para funcionar

63 G. PETERS, Institutional Theory in Political Science: The "New Institutionalism", Routledge, 1999. Esta obra se encuentra traducida al castellano como El nuevo institucionalismo. Teoría institucional en Ciencia Política, Gedisa, Barcelona, 2003.

64 P. A. HALL Y R. TAYLOR, "Political Science and the Three New Institutionalism", Political Studies, XLIV, 1996, pp. 936-957.

65 El citado PETERS (1999) se refiere a siete versiones del nuevo institucionalismo: institucionalismo normativo, de elección racional, histórico, empírico, sociológico, de representación de intereses e institucionalismo internacional.

${ }^{66}$ G. CABALLERO MÍGUEZ, "Nuevo institucionalismo en Ciencia Política, institucionalismo de elección racional y análisis político de costes de transacción: una primera aproximación", Revista de Investigaciones Políticas y Sociológicas, vol. 6, núm. 2, 2007, pp. 9-27.

${ }^{67}$ Ibidem, p. 15.

${ }^{68}$ Ibidem, p. 21. 
satisfactoriamente. Esta información y transparencia harán más adecuadas la formación institucional, su diseño y su posible cambio.

Por lo tanto, desde un sentido (politológico) normativo la transparencia del sistema público es imprescindible para proveer información que permita tomar decisiones racionales, que son las decisiones que mejor se corresponden con el interés general de la comunidad. Si desde la óptica (también politológica) positiva la realidad muestra un déficit de transparencia de las instituciones públicas, habrá que implementar las acciones y reformas oportunas para revertir la situación y encaminarla a la deseable (punto de vista normativo de nuevo).

\section{TRANSPARENCIA Y BUEN GOBIERNO: UNA PRECISIÓN ADICIONAL}

En la normativa española parece que se ha vuelto característico conectar, en el Derecho positivo, las previsiones de transparencia y las de buen gobierno, a pesar de tratarse de conceptos distintos. Ahora solo vamos a efectuar un par de apuntes de esta cuestión, pues hay un artículo específico de buen gobierno en este número especial de Dereito.

Tanto la ley gallega como la estatal regulan en el mismo cuerpo normativo la transparencia y el buen gobierno. De igual forma lo hacen las leyes de Castilla-La Mancha (Ley 4/2016), Cataluña (Ley 19/2014), Extremadura (Ley 4/2013), Islas Baleares (Ley 4/2011), La Rioja (Ley 3/2014), Navarra (Ley Foral 11/2012), Región de Murcia (Ley 12/2014) y Comunidad Valenciana (Ley 2/2015). El buen gobierno es un principio de ética general que busca un comportamiento y unas actuaciones en cierto sentido de los responsables públicos. Se prevén, así, entre otras cosas, incompatibilidades y acciones ante conflictos de intereses. Se indica que las personas que ocupen altos cargos deben ser íntegras, honestas, imparciales y objetivas (art. 2.h LGT).

La Ética y el Derecho son dos ámbitos diferentes, aunque ambos sirven para regular la vida en sociedad. La Ética es una disciplina filosófica que estudia el bien y el mal de la actuación humana, sirviendo de fundamento a las normas morales (las cuales pretenden regir el comportamiento de las personas). Como afirma Bertrand Russell, el fin de la Ética es descubrir proposiciones verdaderas acerca de la conducta virtuosa y viciosa ${ }^{69}$. Dentro de la Ética se podría situar la axiología (estudio de valores). En cambio, el Derecho es un conjunto preferentemente de normas jurídicas que regulan la vida en sociedad tratando de aplicar un punto de vista determinado de la justicia. Su origen está en los órganos de producción normativa, que son los que concretan las realizaciones de la justicia en las normas jurídicas. Una de sus notas características del Derecho es la coactividad, esto es, la posibilidad de imposición por la fuerza. Tal característica no se encuentra en otras formas de regulación social.

Durante tiempo se discutió la necesidad de separar convenientemente el Derecho de la Ética y de los valores. Se entendía que la técnica jurídica se

${ }^{69}$ B. RUSSELL, Ensayos filosóficos, 3a ed., Alianza, Madrid, 2018, p. 14. 
resentía con tales confusiones ${ }^{70}$. Sin embargo, tras la II Guerra Mundial, en el marco de reconstrucción del Derecho Público europeo y del nuevo constitucionalismo material que se impuso después de la contienda, al Derecho se incorporaron valores. De este modo, el art. 1 de la Ley Fundamental de Bonn se ha usado por la doctrina y jurisprudencia para crear el sistema de valores del ordenamiento alemán (y contraponerlo a la neutralidad en este sentido de la Constitución de Weimar). Y la Constitución española de 1978 es quizá el ejemplo más palmario al referirse literalmente a "valores superiores" en su art. 1.1. Como apunta Peces Barba, dicho artículo expresa "el esfuerzo por superar el positivismo que se cierra a consideraciones éticas de contenido (...) y al mismo tiempo no quiere expresar sus criterios éticos con lenguaje iusnaturalista" ${ }^{171}$.

Semeja que estemos ante un paso más en este proceso de crecimiento axiológico de los ordenamientos jurídicos, que ahora incorporan al Derecho el buen gobierno y los códigos éticos. Se diría que se trata de un proceso irreversible en un contexto de regeneración de la vida pública ante la corrupción y la desafección ciudadana. Al incluir en una ley contenidos propios de la ética se juridifican, aunque en el caso gallego exista un problema con las garantías efectivas del buen gobierno (remitimos de nuevo al artículo correspondiente en este número). Sea como fuere, hay que reclamar precisión jurídica para mantener la distinción conceptual entre Derecho y Ética y Moral.

En suma, lo que parece pretender el legislador (estatal y gallego) es ofrecer un paquete normativo que ayude a superar la aludida situación de desafección y, por ende, de mengua de la legitimidad. Y lo hace aunando en la misma ley el principio jurídico de transparencia con el principio ético de buen gobierno (que se juridifica al positivizarse, como hemos dicho). De todos modos, hubiera sido mejor haber aprobado leyes diferentes, una de transparencia y otra de buen gobierno. De hecho, en el plan de regeneración democrática se aprobaron otras leyes, como la citada Ley gallega $7 / 2015$, de iniciativa legislativa popular y participación ciudadana en el Parlamento de Galicia. Fusionar en el mismo texto legal transparencia y buen gobierno ha sido producto más bien de una moda de imitación, y no una exigencia de técnica jurídica.

\footnotetext{
${ }^{70}$ Así, Carl Schmitt critica cómo en la República Federal Alemana la penetración de la filosofía de los valores "transforma la estructura tradicional de los conceptos de constitución, legislación y jurisdicción" (C. SCHMITT, "La tiranía de los valores", Revista de Estudios Políticos, núm. 115, 1961, p. 67). Schmitt considera en este artículo que los valores forman parte de un sistema de puro perspectivismo o de un sistema de referencias (p. 71) y denuncia el peligro de la lógica del sinvalor (p. 74). Forsthoff también señala los riesgos de los valores en un trabajo publicado en uno de los homenajes a Schmitt (E. FORSTHOFF, "Die Umbildung des Verfassungsgesetzes", en H. BARION, E. FORSTHOFF y W. WEBER -coords.-, Festschrift für Carl Schmitt, Duncker \& Humblot, Berlín, 1959, pp. 35 y ss.).

${ }^{71}$ G. PECES BARBA, Los valores superiores, Tecnos, Madrid, 1986, p. 52. En la página siguiente apunta que la expresión valores superiores busca superar la antítesis iusnaturalismo-positivismo; y que "no es un planteamiento positivista, ya que habla de los valores, ni tampoco iusnaturalista, porque están positivados y son históricos".
} 


\section{CONCLUSIONES}

Como hemos visto, un cúmulo de ideas está en la base del actual principio de transparencia que la legislación positiva ya contempla extensamente en España. La LGT forma parte de este corpus normativo, por lo que sus motivaciones pueden considerarse las mismas que las del resto de leyes de transparencia. Tal vez los que elaboraron tales leyes no reflexionaron sobre esta base epistemológica tan significativa, sino que respondieron a lo que ya venía exigido por la opinión pública y el Derecho Comparado. Sin embargo, ello no resta fuerza a este trasfondo ideológico y teórico, que nos permite comprender mejor la relevancia que la transparencia tiene para la calidad de nuestra democracia. La transparencia es un elemento constitutivo y nuclear de la misma, pues como apunta Sorrentino, el poder invisible y el recurso al secreto no son solo un simple obstáculo para la plena realización de la democracia, sino que son también "un factor de verdadera degeneración de tal forma de gobierno"72.

Nos congratulamos de que Galicia abriera el proceso en España en el 2006 y ahora haya aprobado una nueva y más moderna ley en la materia. Esperemos que dé buenos frutos porque aunque la normativa es un poderoso aliado para conformar la dinámica social y pública, es cierto que no resulta por sí sola suficiente. Necesita del compromiso de los responsables políticos y administrativos, además de los aplicadores jurídicos y de los garantes del sistema. Tiempo habrá para analizar la actuación de unos y de otros porque estamos convencidos de que la democracia inteligente que hemos preconizado en páginas anteriores impondrá continúas evaluaciones, tanto formalizadas como fácticas, en este terreno.

Aunque persistan problemas técnico jurídicos (la transparencia es tratada como un principio que contiene en su interior un derecho; o que el buen gobierno también se haya incorporado a la categoría de transparencia), lo que nos resulta más inquietante presenta una dimensión sociopolítica, que afecta a la esencia misma de la democracia participativa, a cuyo servicio está la transparencia. Nos referimos a que la gente no participa como cabría pensar. Hay desde hace tiempo instrumentos y mecanismos para ello, pero se usan con escasez. El problema quizá sea ¿participar para qué? Es decir, que el sistema público no ha convencido todavía a la ciudadanía para participar al no saber mostrar las fortalezas de dicha participación ${ }^{73}$. Se nos antoja relevante reflexionar ante esta cuestión para encontrar soluciones.

En definitiva, la democracia participativa, y la democracia inteligente que proponemos para el futuro inmediato, exigen un nivel adecuado de transparencia, esto es, real y efectivo, que sea consecuencia de la nueva cultura que debe anidar en el poder público. Hay que gobernar con la

\footnotetext{
${ }^{72}$ V. SORRENTINO, "Discusión pública...", op. cit., p. 21.

73 Sobre esta cuestión hablamos, en parte en tono coloquial, en la mesa sobre investigación y conocimiento en el gobierno abierto en el Opengov Leadership Summit 2017 La Nucía, el 19 de octubre de 2107, lo que se puede ver en la dirección https://www.youtube.com/watch?v=77f113gdeQQ (a partir de 7:26:05).
} 
ciudadanía, integrarla en los procesos de toma de decisión, y apostar por mayor compromiso ecológico y con los derechos fundamentales. Se nos abre, pues, un reto fascinante, un reto que parte de un verdadero proceso de fortalecimiento democrático que tiene en el principio de transparencia un instrumento imprescindible.

\section{BIBLIOGRAFÍA CITADA}

ALMONACID MENDIETA, V., "El largo camino hacia la transparencia en los ayuntamientos españoles", El consultor de los ayuntamientos, núm. 18, Especial Transparencia en la actividad municipal, pp. 1983-2001.

ARANDA ÁLVAREZ, E., "El marco constitucional de los servicios de inteligencia", en D. NAVARRO BONILLA y M. A. ESTEBAN NAVARRO (coords.), Gestión del conocimiento y servicios de inteligencia, Universidad Carlos III - Boletín Oficial del Estado - Instituto Español de Estudios Estratégicos, Madrid, 2004, pp. 155-180.

BACON, F., El avance del saber, Alianza, Madrid, 1988,

BLANCO VALDÉS, R. L., La construcción de la libertad, Alianza, Madrid, 2010.

BOBBIO, N., El futuro de la democracia, Fondo de Cultura Económica, $3^{a}$ ed., México D. F., 2014.

BODIN, J., Los seis libros de la república, Tecnos, Madrid, 2006.

BRANDEIS, L. D., Other People's Money, and how the Bankers use it, Frederick A. Stokes Company, Nueva York, 1914.

CABALLERO MÍGUEZ, G., "Nuevo institucionalismo en Ciencia Política. Institucionalismo de elección racional y análisis político de costes de transacción: una primera aproximación", RIPS, vol. 6, núm. 2, 2007, pp. 9-27.

COTINO HUESO, L., "Del «deber de publicidad» de Brandeis al «open government» de Obama. Regulación y control de información pública a través de las nuevas tecnologías", en G. ESCOBAR ROCA, La protección de los derechos humanos por las defensorías del pueblo, Dykinson, Madrid, 2013, pp. 859-885.

FERNÁNDEZ RODRÍGUEZ, J. J., La inconstitucionalidad por omisión. Teoría general. Derecho Comparado. El caso español, Civitas, Madrid, 1998.

FERNÁNDEZ RODRÍGUEZ, J. J., "La libertad de imprenta en las Cortes y en la Constitución de Cádiz de 1812", Dereito. Revista xurídica da Universidade de Santiago de Compostela, vol. 12, núm. 1, 2003, pp. 37 y ss.

FERNÁNDEZ RODRÍGUEZ, J. J., Lo público y lo privado en Internet. Intimidad y libertad de expresión en la Red, Universidad Nacional Autónoma de México, México D. F., 2004.

FERNÁNDEZ RODRÍGUEZ, "Lo neopúblico: un nuevo espacio en Internet para el ejercicio de los derechos fundamentales", en PÉREZ ROYO, Javier; URÍAS MARTÍNEZ, Joaquín; CARRASCO DURÁN, Manuel (editores), Derecho Constitucional para el siglo XXI. Actas del VIII Congreso Iberoamericano de Derecho Constitucional, vol. I, Aranzadi, Pamplona, 2006, pp. 1233 y ss. 
FERNÁNDEZ RÓDRIGUEZ, J. J., Los fundamentos del Derecho Constitucional (Derecho, Estado y Constitución), Centro de Estudios Constitucionales, Tribunal Constitucional del Perú, Lima, 2008.

FERNÁNDEZ RODRÍGUEZ, J. J., "La transparencia pública como exigencia democrática", Advocatus, núm. 29, 2013, pp. 21-26.

FERNÁNDEZ RODRÍGUEZ, J. J., Defensorías del pueblo en España: una visión prospectiva, Universidad de Alcalá, Madrid, 2014.

FORSTHOFF, E., "Die Umbildung des Verfassungsgesetzes", en $\mathrm{H}$. BARION, E. FORSTHOFF y W. WEBER -coords.-, Festschrift für Carl Schmitt, Duncker \& Humblot, Berlín, 1959, pp. 35 y ss.

GARCÍA MORALES, M. J., Transparencia y rendición de cuentas de las relaciones de cooperación intergubernamental en el Estado autonómico, Generalitat de Catalunya, Barcelona, 2017.

GUICHOT REINA, E., "Transparencia y acceso a la información pública en España: análisis y propuestas legislativas", en http://www.fundacionalternativas.org/public/storage/laboratorio_docu mentos archivos/a1d04f2c5f4e94e441966c1b79f39fa3.pdf

GUICHOT REINA, E. (coord.), Transparencia, acceso a la información pública y buen gobierno, Tecnos, Madrid, 2014.

HABERMAS, J., Theorie des Kommunikativen Handelns, Suhrkamp, Frankfurt, 1981. En castellano, Teoría de la acción comunicativa, Taurus, Madrid, 1987.

HAMILTON, A.; MADISON, J.; JAY, J., O Federalista, Universidad de Santiago de Compostela, 2016.

HAN, B-C., La sociedad de la transparencia, Herder, Barcelona, 2013.

HALL, P. A. y TAYLOR, R., "Political Science and the Three New Institutionalism", Political Studies, XLIV, 1996, pp. 936-957.

HOBBES, T., Leviathan, Cambridge University Press, Cambridge, 1991. En castellano hemos citado Leviatán, Alianza, 2a ed., Madrid, 2017.

KANT, I., Zum ewigen Frieden. Ein philosophischer Entwurf, Friedrich Nicolovius, Königsberg, 1795.

LANCINA, J. A. de, Comentarios políticos a los Anales de Cayo Vero Cornelio Tácito, Imprenta Melchor Álvarez, Madrid, 1687.

$M A R C H$, J. G. y OLSEN, P., "The new institutionalism: organizational factors in political life", American Political Science Review, núm. 78, 1984, pp. 738-749.

MARCH, J. G. y OLSEN, P., Rediscovering Institutions, Free Press, Nueva York, 1989.

MARTÍ, J. L., La democracia deliberativa, Marcial Pons, Madrid, 2006.

MEINECKE, F., La idea de la razón de Estado en la edad moderna, Centro de Estudios Constitucionales, Madrid, 1983.

MILL, J. S., On Liberty, John Parker and Sohn, Londres, 1859. En castellano, por ejemplo, Sobre la Libertad, Alianza, Madrid, 1997.

MILL, J. S., Considerations on Representative Government, Parker, Son and Bourn, Londres, 1861.

MORERA DE LA VALL, H. W., Secretos de Estado y Estado de Derecho: régimen jurídico de los secretos oficiales en España, Atelier, Barcelona, 2007. 
PECES BARBA, G., Los valores superiores, Tecnos, Madrid, 1986.

RUBIO LLORENTE, F., Derechos fundamentales $y$ principios constitucionales, Ariel Derecho, Barcelona, 1995.

RUSSELL, B., Ensayos filosóficos, 3a ed., Alianza, Madrid, 2018.

RUIZ MIGUEL, C., Servicios de inteligencia y seguridad en el Estado Constitucional, Tecnos, Madrid, 2002.

SÁNCHEZ FERRO, S., El secreto de estado, Centro de Estudios Políticos y Constitucionales, Madrid, 2006.

SCHMITT, C., Verfassungs/ehre, Duncker \& Humblot, 1928. En castellano, por ejemplo, Teoría de la Constitución, Alianza, Madrid, 1982.

SCHMITT, C., "La tiranía de los valores", Revista de Estudios Políticos, núm. 115, 1961, pp. 65 y ss.

SCHMITT, C., La dictadura, Alianza Editorial, Madrid, 1985.

SCHMITT, C., Sobre el parlamentarismo, Tecnos, Madrid, 1996.

SORRENTINO, V., Il potere invisibile. Il segreto e la menzogna nella política contemporánea, Dedalo, Bari, 2011.

SORRENTINO, V., "Discusión pública y transparencia del poder en Hobbes y Kant", Laguna: Revista de Filosofía, núm. 36, 2015, pp. 21 y ss.

SPINOZA, B., Tratado teológico-político. Tratado político, Tecnos, Madrid, $4^{\mathrm{a}}$ ed., 2007.

TÁCITO, C., Anales, Alianza, Madrid, 1996.

TRUYOL Y SERRA, A., Historia de la Filosofía del Derecho y del Estado, tomo II, Alianza, $3^{a}$ ed., Madrid.

VARELA SUANZES-CARPEGNA, J., Tres ensayos sobre Historia constitucional, Universidad Inca Garcilaso de la Vega, Lima, 2008.

WEBER, M., Economía y sociedad, Fondo de Cultura Económica, México D. F., 1964. 